\title{
The challenges of androgen insensitivity syndrome
}

Bratu Ovidiü, ${ }^{1,2}$ Dragos R. Marcu, ${ }^{1,2}$, Dan L. D. Mischianu ${ }^{1,2}$, Catalina Poiana ${ }^{2,3}$, Camelia C. Diaconu ${ }^{2,4}$, Simona G. Bungau ${ }^{5}$, Delia M. Tit ${ }^{5}$, Alin Cumpanas ${ }^{6}$, Roxana Bohiltea ${ }^{2,7}$

${ }^{1}$ Central Military Hospital Bucharest, Romania

¿University of Medicine and Pharmacy, Bucharest, Romania

${ }^{3}$ Parhon Hospital, Romania

${ }^{4}$ Floreasca Emergency Clinical Hospital, Romania

${ }^{5}$ Faculty of Medicine and Pharmacy, University of Oradea, Romania

${ }^{6}$ University of Medicine and Pharmacy, Timisoara, Romania

${ }^{7}$ University Emergency Hospital of Bucharest, Romania

Submitted: 1 May 2020; Accepted: 21 July 2020

Online publication: 15 March 2021

Arch Med Sci 2022; 18 (4): 881-889

DOI: https://doi.org/10.5114/aoms/125584

Copyright $\odot 2021$ Termedia \& Banach

\section{Abstract}

Androgen insensitivity syndrome (AIS) is an X-linked recessive genetic syndrome that occurs as result of an androgen receptor mutation; it affects the normal masculinization process in chromosomal male patients. More than 900 androgen receptor mutations that can lead to AIS have been identified. The complete androgen insensitivity is characterized by a total lack of response to androgens, usually in patients with 46XY karyotype but with feminine phenotype. Primary amenorrhoea and inguinal swellings in female patients are the main signs that could raise suspicion for this syndrome. Patients with partial androgen insensitivity have ambiguous genitalia at birth and gynecomastia during puberty, whereas those with mild androgen insensitivity present a normal male phenotype but altered spermatogenesis during adulthood and pubertal gynecomastia. The diagnosis of AIS often proves to be a challenge; its management is complex and requires a multidisciplinary approach to meet decision-making challenges in sex assignment, fertility and timing of gonadectomy, psychological outcomes and genetic counselling.

Key words: Morris syndrome, androgen receptor, ambiguous genitalia, 46XY karyotype, testicular cancer, androgen insensitivity types.

\section{Introduction}

Androgen insensitivity syndrome (AIS) is an X-linked recessive genetic condition, characterized by malformations that appear as a result of an androgen receptor (AR) mutation. This mutation interferes with and disrupts the normal interaction between androgens and their receptors. Androgen insensitivity syndrome implies the existence of a partial or total lack of response or sensitivity of androgen receptors to androgen stimulation [1]. This alters the masculinization process in chromosomal male patients (46XY karyotype) and will lead to the development of a phenotype that can range from normal female external genitalia to normal male external genitalia, but with various degrees of infertility and gynecomastia. These anatomical characteristics are consistent with the degree of androgen receptor sensitivity to the androgen stimulation [2]. Complete, partial, and mild androgen insensitivity syndromes fall into
Corresponding authors: Assoc. Prof. Roxana Bohiltea $\mathrm{MD}, \mathrm{PhD}$

Department of Obstetrics and Gynecology

'Carol Davila' University of Medicine and Pharmacy Dionisie Lupu 37

020021 Bucharest, Romania E-mail: r.bohiltea@yahoo.com

Prof. Assist. Dragos R. Marcu MD Department of Urology 'Carol Davila' University of Medicine and Pharmacy Dionisie Lupu 37

020021 Bucharest, Romania E-mail:

marcuradudragos@yahoo.com 
the generic category of 46XY disorder of sex development.

In the literature data, the first descriptions of the effects of AIS took the form of comprehensive descriptions of intersex characteristics or individual case reports $[3,4]$. Since the $16^{\text {th }}$ century, descriptions, criteria and taxonomies for the classification of intersexuality have been developed by physicians of the time [3-6]. Scientists have used the term "hermaphrodite" as the basis of their taxonomies. The first full description of the AIS dates back to the mid-20 $0^{\text {th }}$ century, when Morris presented 82 female patients with bilateral testes; he initially described this condition as "testicular feminization syndrome" [7]. Later, as a consequence of a better understanding of the pathophysiology involved, the syndrome was renamed AIS [1], which is the currently accepted medical terminology.

Androgen insensitivity syndrome has complex and varied clinical manifestations which pose many challenges for physicians and patients. The clinical manifestations may be specific to each phenotype, depending on the degree of androgen insensitivity.

\section{Material and methods}

This narrative review summarizes and critically appraises the current evidence on genetics and the specific challenges of each type of AIS. The authors of the present study conducted an extensive review of numerous published articles and systematic studies on this topic. Using appropriate keywords or combinations thereof (androgen receptor, Morris syndrome and ambiguous genitals), the PubMed database was accessed, and Englishlanguage publications were selected.

\section{Results}

Genetic anomalies in androgen insensitivity syndrome

According to the literature, an AR gene mutation can be identified in $>95 \%$ of complete AIS (CAIS) cases, out of which approximately two thirds of these mutations are inherited through the maternal line, while the remaining one third are de novo mutations [8]. The AR gene is located in the $\mathrm{Xq11-13}$ region of the $\mathrm{X}$ chromosome and contains 8 exons that encode the androgen receptor [8-10]. The AR is a large polypeptide (containing 920 amino acids) that belongs to the steroid hormone receptor family and it presents 4 functional domains (Table I) [11-19].

\section{Fetal development genetics}

The differentiation of the human embryo into the male sex is regulated by the sex-determining region $Y$ gene (SRY), which is located on Yp 11.2.
SRY encodes the testes determining factor (TDF), which has a crucial role in the initiation of male sex determination. This protein (TDF) is responsible for activation of two other proteins, SOX9 and SF1 (steroid genetic factor 1), which promote differentiation of the bipotent cells of the embryonic gonads into Sertoli cells, therefore leading to the appearance of the primordial testes. These two proteins (SOX9 and SF1) regulate the Sertoli cells' production of anti-Mullerian hormone (AMH), which suppresses the development of the uterus and fallopian tubes from the Mullerian ducts, favouring instead the development of the Wolffian ducts. Leydig cells maturation is promoted by the Desert Hedgehog protein $(\mathrm{DHH})$, which is produced by Sertoli cells. It has been reported that anomalies of this protein can be responsible for 46XY gonadal abnormal development [20-26]. Another factor involved in the male sexual differentiation process is fibroblast growth factor 9 (FGF), which is activated by the SOX9 protein. The absence of FGF9 can be responsible for the reversal of male to female phenotype [27].

In 46XX embryos, the absence of the $Y$ chromosome explains the differentiation of the primordial bipotent embryonic gonad cells into ovaries, as well as the development of the fallopian tubes, uterus, cervix and the proximal part of the vagina from the Mullerian ducts. The absence of the SRY gene and TDF will determine the atrophy of the Wolffian ducts. In the absence of androgens, the clitoris will develop from the genital tubercle and the labia from the labial-scrotal folds [8].

In 46XY embryos with AIS, the activity of the SRY gene and TDF protein is normal, favours the development of the male gonads and inhibits the development of the uterus, fallopian tubes, cervix and upper part of the vagina via AMH action. During the intrauterine life, the normal virilisation process usually takes place between the $8^{\text {th }}$ and the $14^{\text {th }}$ week [28]. This process depends on androgen production and AR capability to bind the androgens. Therefore, the existence of a mutation that affects the androgen production or the androgen receptor will impair the normal virilisation process in 46XY embryos. Due to the insensitivity of androgen receptors to testosterone and dihydrotestosterone, AIS embryos will develop different phenotypes according to AR sensitivity to androgens, this varying from a complete feminine phenotype (in complete androgen insensitivity) to a male phenotype, but with altered spermatogenesis (mild androgen insensitivity). There is an intermediate form, characterized by partial androgen insensitivity, which leads to a male phenotype (usually these patients have associated malformations such as micropenis, hypospadias, bifid scrotum) or to ambiguous genitalia [29]. 
Table I. Functional domains of the androgen receptor gene

\begin{tabular}{|c|c|}
\hline $\mathrm{N}$-terminal domain (NTD) & $\begin{array}{l}\text { - Encoded by exon } 1 \\
\text { - Contains a polymeric amino acid region that includes glycine and glutamine repeats } \\
\text { (GGN and CAG) } \\
\text { - Contains the transactivation function } 1 \text { region (AF1), known as transcription activation } \\
\text { unit } 1 \text { (TAU1) [11-13] } \\
\text { - Involved in the transcription regulation process } \\
\text { - Extength interferes with AR transcription activity } \\
\text { process } \\
\text { - FxxLF ( } \text { - phenylalanine, } L-\text { leucine, } x \text { - any other amino acid) acts as a coactivator } \\
\text { in the transcription activation process } \\
\text { - The length of the polyglutamine region correlates with the risk of genital anomalies } \\
\text { and also with the risk of prostate cancer (when the polyglutamine repeat region is } \\
\text { shorter) [11-13] } \\
\text { - A larger polyglutamine repeat seems to be associated with the risk of Kennedy } \\
\text { disease, which consists in spinal bulbar muscular atrophy [14] }\end{array}$ \\
\hline DNA-binding domain (DBD) & $\begin{array}{l}\text { - Encoded by exons } 2 \text { and } 3 \\
\text { - Presents } 2 \text { zinc protein modules, the first being involved in establishing the contact } \\
\text { with the DNA, while the second modulates this interaction and the DNA dimerization } \\
\text { process } \\
\text { - The structure depends on the interaction between cysteine and the zinc ion. } \\
\text { Any cysteine mutation will severely impair the zinc-cysteine interaction and will } \\
\text { lead to complete androgen resistance, despite the fact that testosterone and } \\
\text { dihydrotestosterone can bind normally to the androgen receptor }[15,16]\end{array}$ \\
\hline Hinge region & $\begin{array}{l}\text { - Links the DNA-binding domain with the last functional domain of the androgen receptor } \\
\text { - Exons } 3 \text { and } 4 \text { partially encode this region, which contains the site for AR } \\
\text { phosphorylation }[17,18]\end{array}$ \\
\hline $\begin{array}{l}\text { C-terminal ligand } \\
\text { binding domain (LBD) }\end{array}$ & $\begin{array}{l}\text { - Contains the sites for the binding of androgens, as well as for several other cofactors } \\
\text { involved in transcription and activation functional region2 (AF2) } \\
\text { - AF2 favours interaction between several proteins that act as coregulators with } \\
\text { the N-terminal domain [19] } \\
\text { - In normal conditions, this domain is involved in the interaction of the AR located in } \\
\text { the cytoplasm with the heat shock proteins, which form a complex } \\
\text { - When androgens reach the cytoplasm, it leads to dissociation of the heat shock } \\
\text { proteins from the androgen receptor, making it available for androgens } \\
\text { - Therefore, androgens and the available free androgen receptor form a new complex } \\
\text { that reaches the nucleus and initiates androgen transcription }[8,9]\end{array}$ \\
\hline
\end{tabular}

\section{Type of androgen insensitivity syndrome}

Considering the degree of AR sensitivity to androgen stimulation, this condition can be divided into three different entities: CAIS, partial AIS (PAIS) and mild AIS (MAIS). Based on personal experience and the review of the literature, we have summarised their clinical features, diagnostic and treatment pathways of management in Table II and Figure 1.

\section{Complete androgen insensitivity syndrome}

Association of 46XY karyotype with an external feminine phenotype characterizes CAIS. The undescended testes are usually located in the lower abdomen, but they can also be found at any point along their descending path towards the scrotum (inguinal canals or labia majora). The internal genital organs are absent, as the result of the anti-Mullerian hormone produced by the testes. In almost all cases, the vagina has a shorter length compared with normal female patients and always presents a blind ending. Pubic and axillary hair is usually present in limited amounts, but it can also be completely absent, as a result of androgen insensitivity $[1,8]$. CAIS patients also seem to have a lower average incidence of facial acne during puberty [10, 30]. The oestrogen level is similar to that found in the normal male; several researchers suggest that breast development is the result of cellular unresponsiveness to androgen stimulation, rather than to higher oestrogen production [1]. Another characteristic of these patients is the fact that they are taller than normal females, but shorter than men. This characteristic is related to the presence of a gene involved in the growth process, which is located on the $\mathrm{Y}$ chromosome (growth controlling gene -GCY) [1, 31].

Usually, these patients seek medical examination for primary amenorrhoea. In numerous cases, the suspicion of CAIS is raised during puberty, which usually occurs spontaneously. Puberty onset is debated among researchers, some of them 
Bratu Ovidiu, Dragos R. Marcu, Dan L. D. Mischianu, Catalina Poiana, Camelia C. Diaconu, Simona G. Bungau, Delia M. Tit, Alin Cumpanas, Roxana Bohiltea

Table II. Type of androgen insensitivity syndrome and phenotype characteristics

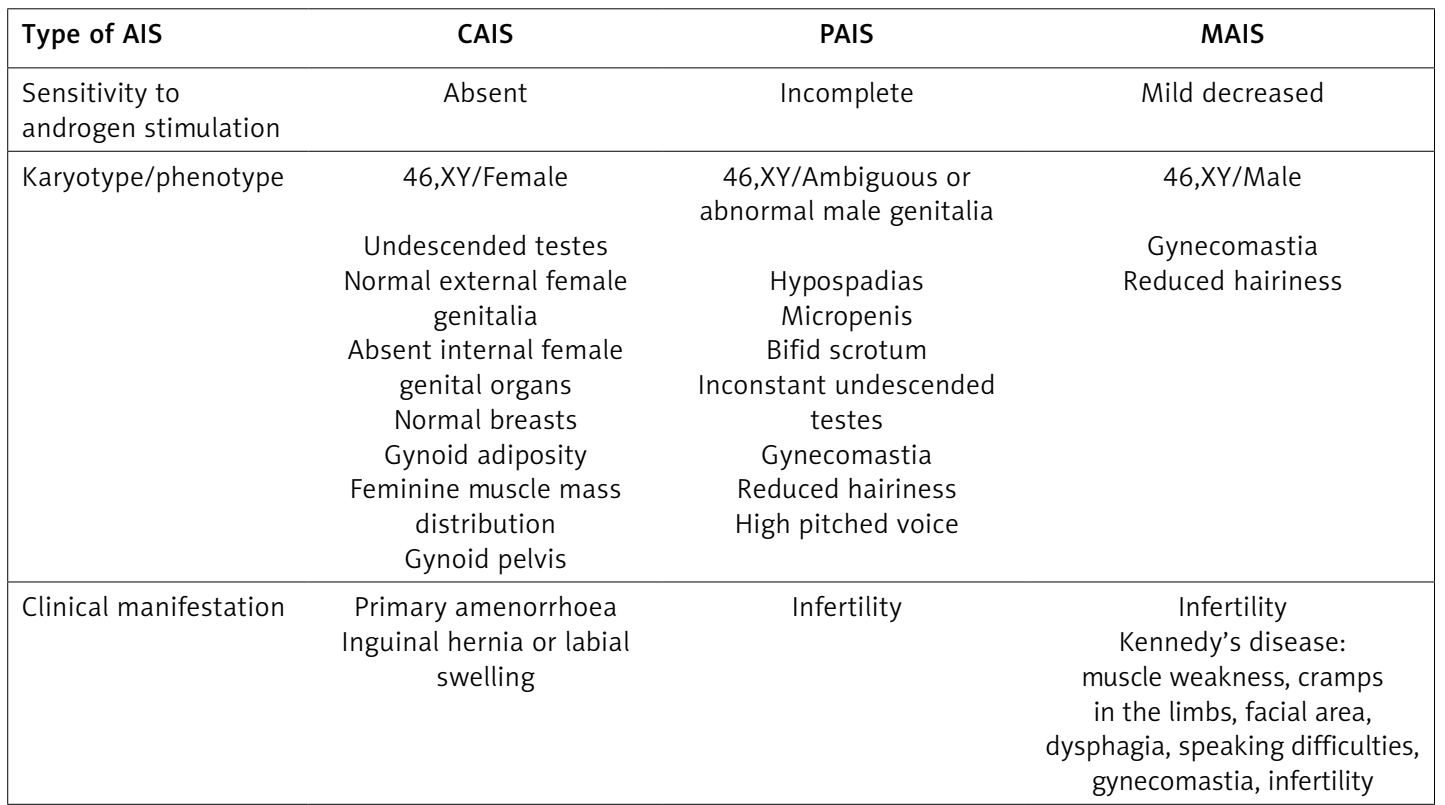
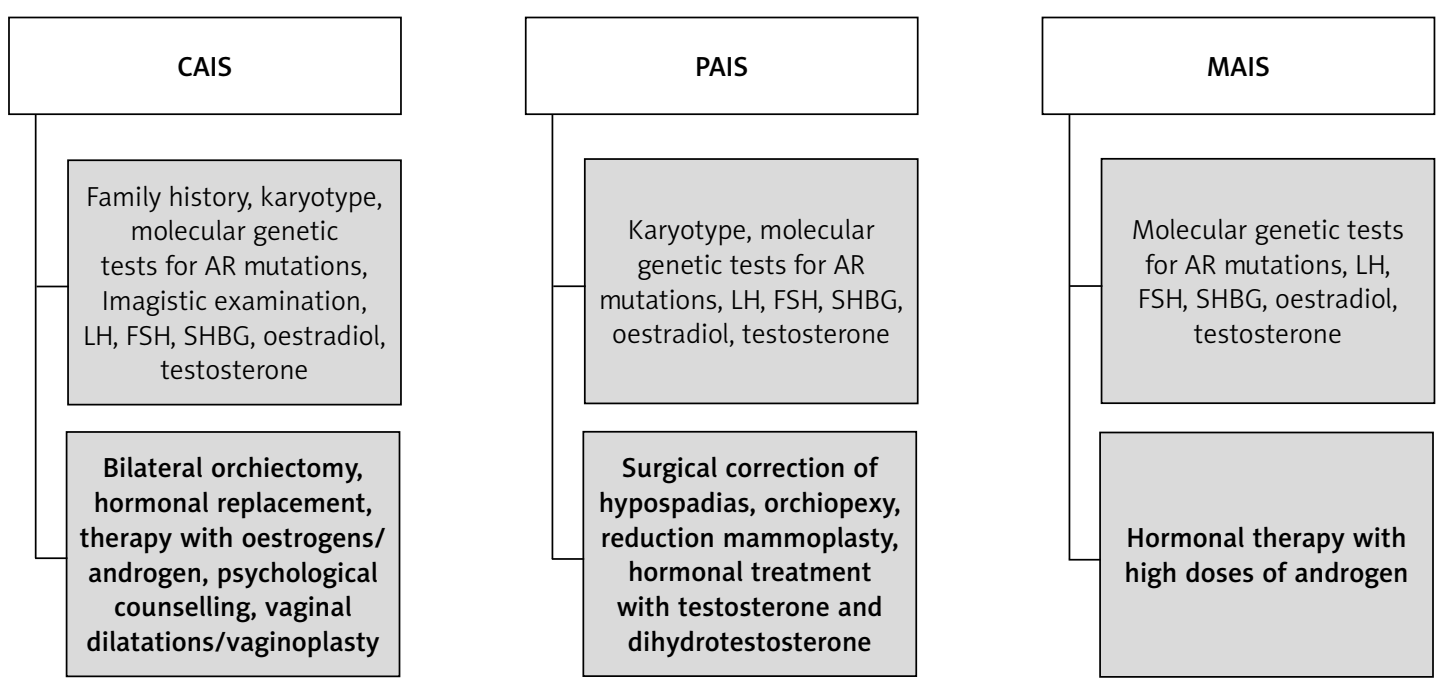

Figure 1. Diagnostic and therapy pathways for the three different types of androgen insensitivity syndrome

reporting that puberty in CAIS patients is initiated in a later stage compared with female patients with 46XX karyotype; however, this hypothesis is not sufficiently supported. Most researchers consider that the moment of puberty onset in CAIS patients is similar to normal female patients [30]. Another scenario that could raise the suspicion of CAIS is the presence of an inguinal hernia or a labial swelling (the testes being located in the labia) in apparently normal female patients during childhood. The presence of a bilateral inguinal hernia in infant female patients is extremely rare. This finding, along with the presence of a short vaginal length, should raise the suspicion of CAIS.

In order to confirm the diagnosis, a karyotype assessment should be considered. Imaging investi- gations, readily available, reveal the absence of the uterus, fallopian tubes and ovaries and the presence of testes. Other elements useful for the diagnosis are family history (the existence of an older sister who has undergone surgery for inguinal hernia repair during childhood), incidental finding of the testes during imaging investigations and the existence of a mismatch between the karyotype and ultrasound findings during fetal life [11].

The oestrogen resulting from the aromatization process of the testosterone and the luteinising hormone (LH) are two key elements involved in puberty onset. In patients with CAIS, serum concentrations of $\mathrm{LH}$ are slightly above the upper values of those observed in men. The values of the follicle stimulating hormone (FSH) and sex- 
ual hormone binding globulin (SHBG) are also in the normal range [12]. In terms of oestradiol levels, its values are usually normal if we consider the male range, but slightly lower than those encountered in female patients. The testosterone levels are above the normal female range, but within the normal male values [13].

The presence of a feminine phenotype at birth, without any signs of external genital organs' virilisation and without secondary male characteristics, is responsible for the fact that these patients are raised for long periods of time as females, having a female gender and identity, in other words considering themselves as being females and having typical feminine activities and interests [8].

After establishing the diagnosis of CAIS, the management of these patients involves bilateral orchiectomy, followed by hormonal replacement therapy with oestrogens, in order to avoid hypo-oestrogens symptoms, as well as psychological counselling. In some cases, vaginal dilatation and even enlargement vaginoplasty may be needed [1]. Bilateral orchiectomy is recommended because undescended testes are associated with a high risk of malignant degeneration after puberty. This risk is very small before adulthood and this allows the recommendation for bilateral orchiectomy to be postponed. Testicular preservation during childhood and adolescence favours normal puberty onset (with breast development and secondary sexual characteristics) under the action of oestrogens that results from androgen aromatization. If orchiectomy is performed before puberty, hormonal replacement therapy is mandatory in order to induce normal puberty [8]. In CAIS infants who have undergone bilateral orchiectomy, oestrogen substitution using either oral or transdermal oestrogen should be initiated at the age of 11-12 years, to induce normal pubertal onset with its specific changes and to obtain complete feminization. The treatment should start with a dose of $2 \mu \mathrm{g}$ of ethinyl-oestradiol administered daily and it should be adjusted periodically over the next 2-3 years, in order to achieve a total daily dose of $30 \mu \mathrm{g}$, which is the normal adult dose [1, 2]. Oestrogen substitution therapy should be continued with a constant daily dose after achieving definitive breast development. A definitive oestrogen dose for the initiation of hormonal replacement therapy has not been defined. Some authors report a higher initiation oestrogen dose, in the range of $2.5-5 \mu \mathrm{g} /$ day or $50-100 \mathrm{ng} / \mathrm{kg}$ daily oestrogen, which will be periodically increased until achieving a total daily dose of approximately 20-25 $\mu \mathrm{g}$. Excessive doses of oestrogen may have a negative impact on the growth process by too early closure of the epiphysis [13, 32, 33].

Dehydroepiandrosterone is the most abundant circulating sex steroid hormone. Although it has no receptors to bind to, restoring the circulating levels of androgen hormones after orchiectomy was found to improve the sexual well-being. This is a clinical observation in CAIS patients after orchiectomy; the mechanism is not fully understood, but it may be explained by the effect of these hormones on brain and sexual development, despite the lack of receptors or receptor mutations.

\section{Partial androgen insensitivity syndrome}

Partial androgen insensitivity syndrome is the result of an incomplete cellular response to androgen stimulation. The phenotype of these patients depends on the degree of androgen receptors' responsiveness to androgen stimulation. Most patients are born with incompletely developed and atypical male genitalia, or ambiguous genitalia at birth. Therefore, establishing the correct gender of new-born patients with genital anomalies and development of an appropriate therapeutic protocol require identification of the presence of an androgen receptor mutation for the diagnosis. Several studies suggest short periods of androgen administration in order to assess the AR response [2, 34].

In terms of hormone profile, these patients usually present high levels of luteinizing hormone and testosterone. In order to exclude the presence of an androgen synthesis defect, testosterone precursors, testosterone and dihydrotestosterone concentrations can be assessed, before and after human chorionic gonadotropin [8].

Most PAIS patients are raised as males. In borderline patients, with ambiguous genitalia, gender assignment should be given as soon as possible, considering the aspect of the genital organs. It is presumed that the more masculinized the genital organs are, the more likely it is that the brain has been virilised $[35,36]$. The management of PAIS patients raised as males involves the surgical correction of hypospadias, orchiopexy, hormonal treatment with testosterone and dihydrotestosterone to induce puberty and to strengthen the virilisation process (it may improve penile length and other secondary sexual characteristics). The results of the androgen treatment can be seen after at least 6 months of treatment. Additional administration of androgen hormones is not always necessary, especially in cases with normal testes and normal testosterone production. For those patients who develop gynecomastia, reduction mammoplasty is necessary. The incidence of breast cancer in PAIS is low [2].

\section{Mild androgen insensitivity syndrome}

Mild androgen insensitivity syndrome is associated with a small degree of androgen insensitivity; these patients present a male phenotype. This type of androgen insensitivity is also the re- 
sult of an androgen receptor mutation, but these patients, in contrast to those with PAIS and CAIS, present normally developed male genitalia. Until now, a small number of androgen receptor mutations that are strictly responsible for MAIS have been reported [1].

Usually, MAIS patients will seek medical advice for infertility, this being the main clue that could lead to the diagnosis. The product of serum testosterone and LH concentrations, used as an index of possible mild AIS in infertile men, could be considered a screening test for the presence of any mutation in the androgen receptor gene. Experimental results (performed in mice) of androgen receptor conditional clearance demonstrate that a functional receptor, expressed in Sertoli and Leydig cells, is essential for normal spermatogenesis [37]. Mild androgen insensitivity syndrome patients can also develop gynecomastia and reduced hairiness. High dose androgen treatment could restore these patients' fertility [1].

Mild androgen insensitivity syndrome can also present as Kennedy's disease, which is characterized by bulbar and spinal muscular atrophy, facial area, dysphagia, speaking difficulties, gynecomastia and infertility [38]. This disease is the result of an AR mutation, consisting in a hyper-expansion of the CAG repeat at the level of exon 1 [2]. Experimental tests in which transgenic mice (with hyper-expanded CAG repeats) were crossed with mice with inactive androgen receptors revealed increased neuromuscular and endocrine reproductive characteristics [39].

Based on the literature review and the authors' personal experience in this field, we recommend the algorithm shown in Figure 1 for diagnosis and treatment of CAIS, PAIS and MAIS entities.

\section{Androgen insensitivity syndrome and testicular cancer}

In the case of AIS patients, the risk for germ cell cancer in gonads varies across the subtypes. It is considered that the number of germ cell tumours increases in individuals, simultaneous with AIS, because of the $Y$ chromosome and presence of the testis-specific protein Y-linked 1 (TSPY) gene $[40,41]$. The literature in the field is not consensual, showing variation of the risks of malignancy in the case of AIS [42-44].

The estimated risk of benign testicular tumours in patients with undescended testes during adulthood is approximately $25 \%$, whereas the risk for malignant testicular tumours is lower, being estimated between $3 \%$ and $10 \%$ [45]. This risk is negligible during childhood and adolescence $(<1 \%)$ in CAIS patients, but it increases with age, being estimated $<3.5 \%$ at 25 years, and as high as $33 \%$ at 50 years [46]. Testicular germ cell tumours (TGCT) are preceded by in situ non-invasive lesions, known as germ cell neoplasia in situ (GCNIS). GCNIS has a 50\% chance of becoming invasive over the following 5 years in the general population. The germ cell tumours associated with AIS correspond to type II seminoma, non-seminoma and dysgerminoma. In terms of benign tumours, the most frequently encountered are hamartomas and Sertoli cell adenoma. Carcinoma in situ originates from the primordial germ cells and it displays a large amount of germ cells in the seminiferous tubules [11, 47].

The low risk of neoplastic degeneration before adulthood allows orchiectomy to be postponed until after puberty. In spite of the risk of malignant degeneration, there are CAIS women who refuse orchiectomy. In such cases, periodic magnetic resonance imaging should be recommended, but this imaging investigation fails to detect germ cell in situ neoplasia [48].

Another recommendation is that the testes should be re-sited in the inguinal canals or at least in their proximity (to ensure a better follow-up) and a testicular biopsy should be performed during the procedure. Several tumour markers can be used to detect the pre-malignant changes characteristic for the carcinoma in situ (PLAP: placental like alkaline phosphatase, SCF: stem cell factor, OCT3/4: octamer binding transcription factor 3/4), but these markers can be used only on testicular tissue samples obtained after biopsy [49-51].

In patients with PAIS and undescended testes, the incidence of testicular malignant degeneration is significantly higher compared to CAIS patients, up to $50 \%$. Therefore, in order to avoid this risk, scrotal orchidopexy should be recommended in all PAIS male patients and laparoscopic orchiectomy in female PAIS patients $[52,53]$.

\section{Androgen insensitivity syndrome and prostate cancer/benign prostatic hyperplasia}

In patients with CAIS, prostate development and masculinization are inhibited by the impaired androgen receptor function, the prostate remaining practically undeveloped.

In PAIS patients, prostate is significantly smaller compared to normal male patients, often being impalpable, whereas MAIS patients usually present a quasi-normally developed prostate. Therefore, the risk of prostate cancer and benign prostatic hyperplasia in patients with CAIS is virtually absent, whereas in patients with partial and mild androgen resistance syndrome this risk can be increased by the exogenous androgen supplementation with testosterone and dihydrotestosterone, as well as by the type of androgen receptor mutation.

Salmasi et al. assessed the PSA levels in 26 patients diagnosed with 46XY disorders of sexual development (including three CAIS cases and nine 
PAIS cases). These authors reported that $18 \mathrm{pa}$ tients presented PSA levels lower than $0.1 \mathrm{ng} / \mathrm{ml}$, half of them being raised as females. The remaining 9 patients presented PSA levels ranging between 0.1 and $0.9 \mathrm{ng} / \mathrm{ml}$ (all of them being raised as males), which were in the same range as those found in normal male patients with similar age and race; therefore these patients could be associated with the same risk of prostate cancer as normal male patients. The authors mentioned that patients raised as females did not present detectable PSA levels and recommended that the screening for prostate cancer using PSA and digital rectal examination in such patients (including PAIS and MAIS cases) should be done as in normal male patients [54].

\section{Discussion}

Among $46 \mathrm{XY}$ disorders in the sex development, AIS is known and recognised as the most common type, characterised by a vast field of clinical heterogeneity [55]; also, it is caused by abnormalities in the AR gene, with phenotypes that vary from CAIS (having a completely female phenotype) to PAIS (having a low degree of infertility or under virilisation) [56]. Each type of AIS presents a series of specific challenges. In the CAIS patient, after bilateral orchiectomy is performed, oestrogen levels will decline. These patients present a high risk of developing osteoporosis, cognitive decline and cardiovascular disease if the oestrogen deficit is not compensated $[13,57]$. In CAIS patients who undergo bilateral orchiectomy after puberty, as well as in those with orchiectomy during childhood and oestrogen substitution therapy during puberty, hormonal replacement therapy consists in a dose of $1 \mathrm{mg}$ of oestradiol administered daily or 40-50 $\mu \mathrm{g}$ administered transdermally. The transdermal approach seems to provide a more physiological reaction [11].

A considerable percentage of CAIS patients who undergo orchiectomy and hormonal oestrogen substitution will complain of a decrease in their general well-being, as well as about sexual dissatisfaction. Numerous patients report a significant decrease of arousal, libido, orgasm incidence and orgasm intensity after gonadectomy. It seems that testosterone administered after orchiectomy in CAIS patients will improve these complaints. Birnbaum compared the effectiveness of androgen substitution therapy in 26 CAIS patients following orchiectomy with the usually prescribed oestrogen hormonal replacement treatment. The authors noted that the two treatment options (androgens and oestrogens) did not differ in terms of their psychological and mental well-being effects, or in their impact on quality of life [58]. Nevertheless, androgen substitution therapy seems to be superior when compared to oestrogen treatment in terms of sexual well-being and orgasmic function [59].

For the PAIS patients assigned and raised as females, the therapeutic protocol implies bilateral orchiectomy during childhood, to prevent the effects of further virilisation and to reduce the risk of testicular cancer, in patients with undescended testes. Further surgery, such as genital reconstruction, is usually needed, to achieve a more natural appearance of the genital organs and also for improving their functionality and the patient's well-being. The success of such procedures significantly improves the patient's quality of life [31]. Hormonal treatment with oestrogen is mandatory, to induce puberty and ensure the proper development of secondary female sexual characteristics. Compared with CAIS patients, PAIS patients are more susceptible to developing anxiety, depression and other psychiatric disorders [60].

In the case of MAIS, information on clinical results is scarce. Infertility and gynecomastia are the usual way of presenting this phenotype [61], mastectomy being the recommended procedure to correct gynecomastia. This phenotype can be observed and found in people diagnosed with Kennedy disease [9].

Psychosexual identification is a major challenge in AIS management. It is considered that the sexual differentiation not only consists in genitalia formation, but also in brain effects of androgens. Psychosexual development is a complex process, many factors being involved, such as genetic influence, hormones, environment, social life, etc. [62, 63]; it includes gender identity, self-identification to a gender and sexual orientation, defined as the response of a person to sexual stimuli. Both can be affected in AIS, because of misalignment between chromosomal, gonadal and phenotypic sex [62].

Patients with CAIS should be raised as females, because of external genitalia development and androgen unresponsiveness of the brain. These patients require psychological advice after the diagnosis is established and regarding the necessity of orchiectomy and acceptance of infertility [64].

Patients with PAIS are raised as males; the female gender is preferred only in cases with severe PAIS. They experience more often psychological distress, $25 \%$ of them suffering from a sexual identity crisis. Psychological support is needed, and a decision of assigned gender is made by the family and medical team $[64,65]$.

In conclusion, androgen insensitivity syndrome is a frequent $46 \mathrm{XY}$ disorder of sex development, the mechanism involved being an AR mutation. The clinical presentation of AIS depends on the AR sensitivity to testosterone and dihydrotestosterone stimulation, varying from male phenotype and infertility to female phenotype with a 46XY kary- 
otype. The diagnosis in patients with mild AIS is made usually during adulthood due to infertility or during puberty due to the development of gynecomastia, whereas in patients with complete androgen insensitivity the diagnosis can be made during pregnancy, at birth, during childhood or adulthood. For cases with PAIS, the diagnosis is made in most cases at birth due to the presence of ambiguous genitalia. The treatment in CAIS patients implies bilateral orchiectomy to prevent malignant degeneration of the testes and hormonal therapy to maintain the normal female phenotype, despite the 46XY karyotype. The timing of gonadectomy has been debated by many authors, but current guidelines recommend postponing it until after puberty, to achieve complete natural feminization and due to the fact that the risk of testicular tumours in CAIS patients is low before adulthood. Compared with CAIS patients, PAIS patients present a higher risk of developing testicular tumours. Establishing the correct sex assignment may be very difficult in PAIS patients, because they present ambiguous genitalia. The management of AIS requires a multidisciplinary team of paediatricians, endocrinologists, gynaecologists, urologists, plastic surgeons and psychiatrists. Psychological counselling should be recommended for these patients and their parents.

\section{Conflict of interest}

The authors declare no conflict of interest.

\section{References}

1. Batista RL, Costa EMF, Rodrigues AS, et al. Androgen insensitivity syndrome: a review. Arch Endocrinol Metab 2018; 62: 227-35.

2. Hughes IA, Davies JD, Bunch TI, Pasterski V, Mastroyannopoulou K, MacDougall J. Androgen insensitivity syndrome. Lancet 2012; 380: 1419-28.

3. Simpson JY. Hermaphroditism. In: Todd RB, editor. Cyclopaedia of Anatomy and Physiology, Vol II. London: Longman, Brown, Green, Longmans, \& Roberts; 1839: 684-738.

4. Furdell EL. Midwifery, obstetrics and the rise of gynaecology: the uses of a sixteenth-century compendium. J History Med Allied Sci 2008; 63: 262-4.

5. Dorsey FY, Hsieh MH, Roth DR. 46,XX SRY-negative true hermaphrodite siblings. Urology 2009; 73: 529-31.

6. Verkauskas G, Jaubert F, Lortat-Jacob S, Malan V, Thibaud $E$, Nihoul-Fékété $C$. The long-term follow-up of 33 cases of true hermaphroditism: a 40-year experience with conservative gonadal surgery. J Urol 2007; 177 . 726-31.

7. McLean JM. The syndrome of testicular feminization in male pseudohermaphrodites. Am J Obstet Gynecol 1953; 6: 1192-211.

8. Gulía C, Baldassarra S, Zangari A, et al. Androgen insensitivity syndrome. Eur Rev Med Pharmacol Sci 2018; 22: 3873-87.

9. Hughes IA, Davies JD, Bunch TI, Pasterski V, Mastroyannopoulou K, MacDougall J. Androgen insensitivity syndrome. Lancet 2012; 380: 1419-28.
10. Eisermann K, Wang D, Jing Y, Pascal LE, Wang Z. Androgen receptor gene mutation, rearrangement, polymorphism. Transl Androl Urol 2013; 2: 137-47.

11. Hughes IA, Werner R, Bunch T, Hiort O. Androgen insensitivity syndrome. Semin Reprod Med 2012; 30: 432-42.

12. Mongan NP, Tadokoro-Cuccaro R, Bunch T, Hughes IA. Androgen insensitivity syndrome. Best Pract Res Clin Endocrinol Metab 2015; 29: 569-80.

13. Lanciotti L, Cofini M, Leonardi A, Bertozzi M, Penta L, Esposito S. Different clinical presentations and management in complete androgen insensitivity syndrome (CAIS). Int J Environ Res Public Health 2019; 16: 1268.

14. Fischbeck KH. A role for androgen reduction treatment in Kennedy disease? Muscle Nerve 2013; 47: 789.

15. Helsen C, Kerkhofs S, Clinckemalie L, et al. Structural basis for nuclear hormone receptor DNA binding. Mol Cell Endocrinol 2012; 348: 411-7.

16. Quigley CA, Evans BA, Simental JA, et al. Complete androgen insensitivity due to deletion of exon $C$ of the androgen receptor gene highlights the functional importance of the second zinc finger of the androgen receptor in vivo. Mol Endocrinol 1992; 6: 1103-12.

17. Cutress ML, Whitaker HC, Mills IG, Stewart M, Neal DE. Structural basis for the nuclear import of the human androgen receptor. J Cell Sci 2008; 121: 957-68.

18. Zhou ZX, Kemppainen JA, Wilson EM. Identification of three proline-directed phosphorylation sites in the human androgen receptor. Mol Endocrinol 1995; 9: 605-15.

19. He B, Wilson EM. Electrostatic modulation in steroid receptor recruitment of LXXLL and FXXLF motifs. Mol Cell Biol 2003; 23: 2135-50.

20. Touzon MS, Garrido NP, Marino R, et al. Androgen insensitivity syndrome: clinical phenotype and molecular analysis in a single tertiary center cohort. J Clin Res Pediatr Endocrinol 2019; 11: 24-33.

21. Gottlieb B, Beitel LK, Nadarajah A, Paliouras M, Trifiro M. The androgen receptor gene mutations database: 2012 update. Hum Mutat 2012; 33: 887-94.

22. Hay CW, McEwan IJ. The impact of point mutations in the human androgen receptor: classification of mutations on the basis of transcriptional activity. PLoS One 2012; 7: e32514.

23. Brüggenwirth $\mathrm{HT}$, Boehmer AL, Lobaccaro JM, et al. Substitution of Ala564 in the first zinc cluster of the deoxyribonucleic acid (DNA)-binding domain of the androgen receptor by Asp; Asn; or Leu exerts differential effects on DNA binding. Endocrinology 1998; 139: 103-10.

24. Hellwinkel OJ, Holterhus PM, Struve D, Marschke C, Homburg N, Hiort O. A unique exonic splicing mutation in the human androgen receptor gene indicates a physiologic relevance of regular androgen receptor transcript variants. J Clin Endocrinol Metab 2001; 86: 2569-75.

25. Batista RL, Rodrigues ADS, Nishi MY, et al. A recurrent synonymous mutation in the human androgen receptor gene causing complete androgen insensitivity syndrome. J Steroid Biochem Mol Biol 2017; 174: 14-6.

26. Canto P, Söderlund D, Reyes E, Méndez JP. Mutations in the desert hedgehog $(\mathrm{DHH})$ gene in patients with 46 , $\mathrm{XY}$ complete pure gonadal dysgenesis. J Clin Endocrinol Metab 2004; 89: 4480-3.

27. Colvin JS, Green RP, Schmahl J, Capel B, Ornitz DM. Maleto-female sex reversal in mice lacking fibroblast growth factor 9. Cell 2001; 104: 875-89.

28. Mendonca BB, Domenice S, Arnhold IJ, Costa EM. 46XY disorders of sex development (DSD). Clin Endocrinol 2009; 70: 173-87.

29. Oakes MB, Eyvazzadeh AD, Quint E, Smith YR. Complete androgen insensitivity syndrome - a review. J Pediatr Adolesc Gynecol 2008; 21: 305-10. 
30. Hashmi A, Hanif F, Hanif SM, Abdullah FE, Shamim MS Complete androgen insensitivity syndrome. J Coll Physicians Surg Pak 2008; 18: 442-4.

31. Danilovic DL, Correa PH, Costa EM, Melo KF, Mendonca BB, Arnhold IJ. Height and bone mineral density in androgen insensitivity syndrome with mutations in the androgen receptor gene. Osteoporos Int 2007; 18: 369-74.

32. Warne GL, Grover S, Zajac JD. Hormonal therapies for individuals with intersex conditions: protocol for use. Treat Endocrinol 2005; 4: 19-29.

33. Hiort O, Reinecke S, Thyen U, et al. Puberty in disorders of somatosexual differentiation. J Pediatr Endocrino Metab 2003; 16 (Suppl 2): 297-306.

34. Hughes IA. Early management and gender assignment in disorders of sexual differentiation. Endocr Dev 2007; 11: 47-57.

35. Zuloaga DG, Puts DA, Jordan CL, Breedlove SM. The role of androgen receptors in the masculinization of brain and behavior: what we've learned from the testicular feminization mutation. Horm Behav 2008; 53: 613-26.

36. van Hemmen J, Veltman DJ, Hoekzema E, Cohen-Kettenis PT, Dessens AB, Bakker J. Neural activation during mental rotation in complete androgen insensitivity syndrome: the influence of sex hormones and sex chromosomes. Cereb Cortex 2016; 26: 1036-45.

37. Wang RS, Yeh S, Tzeng CR, Chang C. Androgen receptor roles in spermatogenesis and fertility: lessons from testicular cell-specific androgen receptor knockout mice. Endocr Rev 2009; 30: 119-32.

38. Finsterer J. Bulbar and spinal muscular atrophy (Kennedy's disease): a review. Eur J Neurol 2009; 16: 556-61.

39. Thomas Jr PS, Fraley GS, Damian V, et al. Loss of endogenous androgen receptor protein accelerates motor neuron degeneration and accentuates androgen insensitivity in a mouse model of $X$-linked spinal and bulbar muscular atrophy. Hum Mol Genet 2006; 15: 2225-38.

40. Cools M, Drop SL, Wolffenbuttel KP, Oosterhuis JW, Looi jenga LH. Germ cell tumors in the intersex gonad: old paths, new directions, moving frontiers. Endocr Rev 2006; 27: 468-84.

41. Looijenga LH, Hersmus R, Oosterhuis JW, Cools M, Drop SL, Wolffenbuttel KP. Tumor risk in disorders of sex development (DSD). Best Pract Res Clin Endocrinol Metab 2007; 21: 480-95.

42. Kravarusic DE, Seguier-Lipszyc EF, Nimri R, Nagelberg N, Freud $\mathrm{E}$. Androgen insensitivity syndrome: risk of malignancy and timing of surgery in a paediatric and adolescent population. Afr J Paediatr Surg 2011; 8: 194-208.

43. Dewhurst CJ, Ferreira HP, Gillett PG. Gonadal malignancy in XY females. J Obstet Gynaecol Br Commonw 1971; 78: 1077-83.

44. Liu AX, Shi HY, Cai ZJ, et al. Increased risk of gonadal malignancy and prophylactic gonadectomy: a study of 102 phenotypic female patients with Y chromosome or Y-derived sequences. Hum Reprod 2014; 29: 1413-9.

45. Deshpande H, Chaudhari S, Sharma S. Complete androgen insensitivity syndrome. J Obstet Gynaecol India 2012; 62 (Suppl 1): 75-7.

46. Hannema SE, ScottIS, Rajpert-De Meyts E, Skakkebaek NE, Coleman N, Hughes IA. Testicular development in the complete androgen insensitivity syndrome. J Pathol 2006; 208: 518-27.

47. Tack LJW, Maris E, Looijenga LHJ, et al. Management of gonads in adults with androgen insensitivity: an in ternational survey. Horm Res Paediatr 2018; 90: 236-46.

48. Nakhal RS, Hall-Craggs M, Freeman A, et al. Evaluation of retained testes in adolescent girls and women with complete androgen insensitivity syndrome. Radiology 2013; 268: 153-60.

49. Looijeng LH, Gillis AJ, Stoop H, Biermann K, Oosterhuis JW. Dissecting the molecular pathways of (testicular) germ cell tumour pathogenesis: from initiation to treatment-resistance. Int J Androl 2011; 34: 234-51.

50. Cools M, Looijenga LH, Wolffenbuttel KP, T'Sjoen G. Managing the risk of germ cell tumourigenesis in disorders of sex development patients. Endocr Dev 2014; 27: 185-96.

51. Wunsch L, Holterhus PM, Wessel L, Hiort O. Patients with disorders of sex development (DSD) at risk of gonadal tumour development: management based on laparoscopic biopsy and molecular diagnosis. BJU Int 2012; 110: 958-65.

52. Kathrins M, Kolon TF. Malignancy in disorders of sex development. Transl Androl Urol 2016; 5: 794-8.

53. Hiort O, Birnbaum W, Marshall L, et al. Management of disorders of sex development. Nat Rev Endocrinol 2014; 10: 520-9.

54. Salmasi AH, Wisniewski AB, Novak TE, Gearhart JP, Migeon CJ, Lakshmanan Y. Prostate screening in patients with 46XY disorders of sex development-is it necessary? J Urol 2008; 180: 1422-6.

55. Jiang X, Teng Y, Chen X, et al. Six novel Mutation analysis of the androgen receptor gene in 17 Chinese patients with androgen insensitivity syndrome. Clin Chim Acta 2020; 506: 180-6

56. Liu Q, Yin X, Li P. Clinical, hormonal and genetic characteristics of androgen insensitivity syndrome in 39 Chinese patients. Repr Biol Endocrin 2020; 18: 34.

57. Tit DM, Bungau S, lovan C, et al. Effects of the hormone replacement therapy and of soy isoflavones on bone resorption in postmenopause. J Clin Med 2018; 7: E297.

58. Birnbaum W, Marshall L, Werner R, et al. Oestrogen versus androgen in hormone-replacement therapy for complete androgen insensitivity syndrome: a multicentre; randomised; double-dummy; double-blind crossover trial. Lancet Diabetes Endocrinol 2018; 6: 771-80.

59. Lek N, Tadokoro-Cuccaro R, Whitchurch JB, et al. Predicting puberty in partial androgen insensitivity syndrome: use of clinical and functional androgen receptor indices. EBioMedicine 2018; 36: 401-9.

60. Engberg $H$, Strandqvist A, Nordenström A, et al. Increased psychiatric morbidity in women with complete androgen insensitivity syndrome or complete gonadal dysgenesis. J Psychosom Res 2017; 101: 122-7.

61. Carmina E. Mild androgen phenotypes. Best Pract Res Clin Endocrinol Metab 2006; 20: 207-20.

62. Fisher AD, Ristori J, Fanni E, Castellini G, Forti G, Maggi M. Gender identity, gender assignment and reassignment in individuals with disorders of sex development: a major of dilemma. J Endocrinol Invest 2016; 39: 1207-24.

63. Bojar I, Pinkas J, Gujski M, Owoc A, Racziewicz D, Rothemberg KG. Postmenopausal cognitive changes and androgen levels in the context of apolipoprotein $\mathrm{E}$ polymorphism. Arch Med Sci 2017; 13: 1148-59.

64. Pritsini F, Kanakis GA, Kyrgios I, et al. Psychological aspects of androgen insensitivity syndrome: two cases illustrating therapeutical challenges. Case Rep Endocrinol 2017; 2017: 8313162.

65. Lew-Starowicz Z, Czajkowska K. Prevalence of sexual dysfunction and associated risk factors in Poland. Arch Med Sci 2022; 18: 1031-40. 